\title{
Pengaruh Pengetahuan dan Sikap Ibu Terhadap Pemberian Makanan Pendamping Asi di Gampong Lambaroh Kecamatan Jaya Kabupaten Aceh Jaya
}

\section{The Influence of Knowledge and Mother's Attitudes Toward Giving Complementary food for Asi in Gampong Lambaroh, Jaya District Aceh Jaya District}

\author{
Syarifuddin *1, Isthafan Najmi ${ }^{2}$ \\ 1 Program Studi Agribisnis, Universitas Abulyatama, Jln. Blang Bintang Lama, Km. 8,5, Aceh Besar, 23373 \\ Indonesia \\ 2. Program Studi Manajemen, Universitas Abulyatama, Jln. Blang Bintang Lama Km. 8,5, Aceh Besar, 23373 \\ Indonessia \\ Koresponden Penulis : syarifuddinhasan767@gmail.com"1 ${ }^{*}$,isthafannajmi@ abulyatama.ac.ad ${ }^{2}$
}

\begin{abstract}
Abstrak
Penelitian untuk mengetahui pengaruh pengetahuan dan sikap ibu terhadap pemerian makanan pendamping Asi. Penelitian ini bersifat deskriptif, metode pengumpulan data secara cacah lengkap, berjumlah 44 responden. Analisa data bivariat, program SPSS. Hasil penelitian bahwa, pengetahuan dan sikap ibu, berpengaruh terhadap pemberian makanan pendamping Asi. Diharapkan kepada ibu yang memiliki bayi untuk lebih sering mengikuti kegiatan posyandu dan penyuluhan yang diadakan di Gampong tersebut, dalam rangka meningkatkan pengetahuan dan mencari informasi kesehatan terutama dengan keterkaitan ketepatan pemberian makanan pendamping Asi.
\end{abstract}

Kata kunci : Pengetahuan, Pendamping, Asi

\begin{abstract}
Research to determine the effect of knowledge and attitudes of mothers on the distribution of complementary foods for breastfeeding. This research is descriptive in nature, the method of collecting data is complete count, totaling 44 respondents. Bivariate data analysis, SPSS program. The results showed that the knowledge and attitudes of the mother influenced the complementary feeding of breast milk. It is hoped that mothers with babies will more often participate in the posyandu and counseling activities held in the village, in order to increase knowledge and seek health information, especially in relation to the accuracy of providing complementary feeding for Asi
\end{abstract}

Keywords: Knowledge, companion, Asi 
Journal of Healthcare Technology and Medicine Vol. 6 No. 2 Oktober 2020

Universitas Ubudiyah Indonesia

e-ISSN : 2615-109X

\section{PENDAHULUAN}

Pertumbuhan balita masih menjadi salah satu masalah kesehatan di Indonesia, terutama ketersediaan Gizi bagi balita, yang berakibat pada gangguan kesehatan. Hal ini berakibat pula pada ketidakseimbangan dalam pertumbuhan, aktivitas berfikir, dan semua hal yang berhubungan dengan kehidupan (Aik, 2009).

Angka gizi kurang pada balita juga memberikan kontribusi terhadap tingginya ratarata angka kematian di Indonesia. Balita yang gizi kurang tidak mempunyai cadangan lemak yang cukup dan sangat sedikit otot. Perkembangan otak menjadi lambat oleh karena anak-anak mengalami insiden penyakit yang tinggi karena tubuh tidak mampu melawan infeksi sehingga tidak dapat lagi melanjutkan pertumbuhannya bahkan mengalami dampak terburuk yaitu kematian, (Areif, 2008).

Tumbuh kembang anak akan terganggu jika makanan pendamping tidak diperkenalkan pada di usia 6 bulan, atau pemberiannya dengan cara yang tidak tepat. Karena di usia 6 bulan, kebutuhan bayi untuk energi dan nutrisi mulai melebihi apa yang disediakan oleh ASI, dan makanan pendamping diperlukan untuk memenuhi kebutuhan tersebut. Pada usia ini perkembangan bayi sudah cukup siap untuk menerima makanan lain. Peraturan Pemerintah No 33 Tahun 2012, memberikan makanan pendamping ASI (MP-ASI) yang tepat sejak umur 6 bulan dan meneruskan pemberian ASI sampai umur 2 tahun. Penerapan pola pemberian makan ini akan mempengaruhi derajat kesehatan

Data dari Dinas Kesehatan Aceh, menyebutkan bahwa secara umum cakupan Angka Kematian Bayi (AKB) di enam tahun terakhir cenderung mengalami peningkatan. Informasi yang bersumber pada dinas kesehatan kabupaten/ kota, diketahui jumlah kematian bayi di Aceh tahun 2015 sebanyak 1.179 jiwa dan jumlah lahir hidup sebanyak 100.265 jiwa. Sedangkan jumlah bayi yang diberikan ASI Eksklusif sebanyak 546 orang (11,9\%). Sedangkan jumlah bayi 0-6 bulan di Kabupaten Aceh Jaya Tahun 2015 adalah 5.957 bayi dan yang mendapat ASI Ekslusif sebesar 53\%. Berdasarkan data dari Puskesmas Jaya, sampai bulan Agustus, 2020. Jumlah balita 6-24 bulan yaitu 619 orang dan yang mendapatkan ASI Ekslusif berjumlah 40 orang 4,5. 
Journal of Healthcare Technology and Medicine Vol. 6 No. 2 Oktober 2020

Universitas Ubudiyah Indonesia

e-ISSN : 2615-109X

Berdasarkan penelitian sebelumnya yang dilakukan oleh (Martini, 2009), beberapa kemungkinan penyebab ibu memberikan makanan pendamping ASI dini pada bayi usia < 6 bulan antara lain, pengetahuan ibu yang kurang tentang MP ASI, tingkat pendapatan orang tua, status pekerjaan ibu, dan tingkat pendidikan ibu. Dari beberapa faktor tersebut, faktor pengetahuanlah yang kemungkinan paling berpengaruh dalam ketepatan waktu pemberian MP-ASI karena jika ibu tidak mempunyai pengetahuan yang cukup maka mereka memberikan MP-ASI terlalu dini pada bayinya dan tidak bervariasi, (Martini, 2009).

Penelitian dilaksanakan di Kelurahan Kestalan karena Kelurahan Kestalan memiliki prevalensi gizi kurang tinggi bila dibandingkan kelurahan lainnya. Penelitian ini dilaksanakan di Surakarta karena Dinas Kesehatan Kota Surakarta telah melaksanakan kegiatan yang melibatkan aspek sosial budaya dan aspek pemberdayaan masyarakat sebagai dasar dalam mensosialisasikan pemberian makanan pendamping ASI (MP-ASI) yang berbasis lokal, kegiatan tersebut adalah orientasi pemberian makanan bayi dan anak (PMBA) dengan sasaran petugas kesehatan, kader Posyandu dan ibu baduta. Tujuan dari kegiatan ini adalah meningkatkan pengetahuan dan sikap ibu terkait pemberian makanan pendamping ASI (MP-ASI) standar WHO, serta dibentuknya Kelompok Pendamping Ibu (KP-Ibu) yang bertujuan untuk selalu memberikan motivasi dan memantau ibu dalam pemberian ASI kepada bayi.

Berdasarkan fenomena di atas, maka peneliti merasa tertarik untuk meneliti lebih lanjut tentang Pengaruh Pengetahuan dan Sikap Ibu Terhadap Pemberian Makanan Pendamping Asi di Kampung Lambaroh Kecamatan Jaya, Kabupaten Aceh Jaya..

\section{METODE PENELITIAN}

Penelitian ini bersifat deskriptif kualitatif Tidak menggunakan teknik sampling, tetapi secara cacah lengkap (mengambil semua populasi) berjumlah 44. orang yaitu semua ibu-ibu yang memiliki bayi berumur $0-24$ bulan. Tempat penelitian dilaksanakan di gampong Lambaroh, Kecamatan Jaya, Kabupaten Aceh Jaya. Penelitian ini dilaksanakan pada bulan Agustus 2020. Analisa data yang digunakan pada penelitian ini adalah analisis menggunakan sistem komputerisasi yaitu program SPSS (Statistic Product and Service Solution), (Hartono, 2008). 


\section{HASIL DAN PEMBAHASAN}

1. Hubungan Pengetahuan ibu dengan pemberian makanan pendamping ASI (MP-ASI) Hasil pengumpulan data Hubungan Pengetahuan ibu dengan pemberian makanan pendamping ASI (MP-ASI), menjadi dua yaitu Baik dan kurang baik, maka untuk lebih jelas dapat dilihat pada tabel dibawah ini:

Tabel 1. Hubungan Pengetahuan Ibu dengan Pemberian Makanan Pendamping ASI di Gampong Labaroh, Kecamatan Jaya, Kabupaten Aceh Jaya

\begin{tabular}{|c|c|c|c|c|c|c|c|c|}
\hline \multirow{3}{*}{$\begin{array}{l}\text { Pengetahuan } \\
\text { Ibu }\end{array}$} & \multicolumn{4}{|c|}{ Pemberian MP- ASI } & \multicolumn{2}{|c|}{ Total } & \multirow[t]{3}{*}{$\alpha$} & \multirow[t]{3}{*}{$\overline{\text { P-Value }}$} \\
\hline & \multicolumn{2}{|c|}{ Baik } & \multicolumn{2}{|c|}{ Kurang Baik } & \multirow[b]{2}{*}{$\mathrm{F}$} & \multirow[b]{2}{*}{$\%$} & & \\
\hline & $\mathrm{F}$ & $\%$ & $\mathrm{~F}$ & $\%$ & & & & \\
\hline Baik & 20 & 76,92 & 6 & 33,33 & 26 & 59,09 & & \\
\hline Kurang Baik & 6 & 23,08 & 12 & 66,67 & 18 & 40,91 & 0,05 & 0,007 \\
\hline Total & 26 & 100,00 & 18 & 100,00 & 44 & 100,00 & & \\
\hline
\end{tabular}

Sumber : Data Primer, Tahun 2020.

Tabe 1. memperlihatkan bahwa, dari 26 orang ibu memiliki pengetahuan yang baik, terdapat 20 orang ibu dengan Pemberian MP-ASI baik, dan 6 orang ibu dengan Pemberian MP-ASI kurang baik, dari 18 orang ibu yang pengetahuan nya kurang baik, terdapat 6 orang ibu dengan Pemberian MP-ASI baik, dan 12 orang ibu dengan Pemberian MP-ASIKurang baik. Setelah dilakukan uji statistik (ujiChiSquare), diperoleh nilai P-Value=0,007 (P-Value<0,05) bahwa ada hubungan pengetahuan ibu dengan pemberian makanan pendamping ASI di Gampong Lambaroh, Kecamatan Jaya Kabupaten Aceh Jaya, $(n=44)$. 
Journal of Healthcare Technology and Medicine Vol. 6 No. 2 Oktober 2020

Universitas Ubudiyah Indonesia

e-ISSN : 2615-109X

2. Hubungan sikap ibu dengan pemberian makanan pendamping ASI

Hasil pengumpulan data hubungan sikap ibu dengan pemberian makanan pendamping ASI di Gampong Lambaroh Kecamatan Jaya, Kabupaten Aceh Jaya $(\mathrm{n}=44)$ menjadi dua yaitu baik dan kurang baik, maka untuk lebih jelas dapat dilihat pada tabel dibawah ini:

Tabel 2. Hubungan Sikap Ibu Dengan Pemberian Makanan Pendamping ASI di Gampong Lambaroh, Kecamatan Jaya, Kabupaten Aceh Jaya .

\begin{tabular}{|c|c|c|c|c|c|c|c|c|}
\hline \multirow[t]{3}{*}{ Sikap Ibu } & \multicolumn{4}{|c|}{ Pemberian MP-ASI } & \multirow{2}{*}{\multicolumn{2}{|c|}{ Total }} & \multirow{3}{*}{$\alpha$} & \multirow{3}{*}{ P Value } \\
\hline & \multicolumn{2}{|c|}{ Baik } & \multicolumn{2}{|c|}{ Kurang Baik } & & & & \\
\hline & $\mathrm{F}$ & $\%$ & $\mathrm{~F}$ & $\%$ & $\mathrm{~F}$ & $\%$ & & \\
\hline Baik & 19 & 73,08 & 5 & 27,78 & 24 & 54,55 & & \\
\hline Kurang Baik & 7 & 26,92 & 13 & 72,22 & 20 & 45,45 & 0,05 & 0,005 \\
\hline Total & 26 & 100,00 & 18 & 100,00 & 44 & 100,00 & & \\
\hline
\end{tabular}

Sumber : Data Primer, Tahun 2020.

Tabel 2. Memperlihatkan bahwa, dari 24 orang ibu memiliki sikap yang baik, terdapat 19 orang ibu dengan Pemberian MP-ASI baik, dan 5 orang ibu dengan Pemberian MP-ASI kurang baik. dan dari 19 orang ibu yang sikap nya kurang baik, terdapat 7 orang ibu dengan Pemberian MP-ASI baik, dan 13 orang ibu dengan Pemberian MP-ASI Kurang baik. Setelah dilakukan uji statistik (ujiChi-Square), diperoleh nilai $\mathrm{P}-$ Value $=0,005(\mathrm{P}-$ Value $<0,05)$ bahwa ada hubungan sikap ibu dengan pemberian makanan pendamping ASI di Gampong Lambaroh, Kecamatan Jaya Kabupaten Aceh Jaya.

\section{Pembahasan}

1. Hubungan Pengetahuan Ibu Dengan Pemberian Makanan Pendamping ASI (MPASI) 
Journal of Healthcare Technology and Medicine Vol. 6 No. 2 Oktober 2020

Universitas Ubudiyah Indonesia

e-ISSN : 2615-109X

Berdasarkan analisa data Hubungan Pengetahuan ibu dengan pemberian makanan pendamping ASI di Gampong Lambaroh, Kecamatan Jaya,Kabupaten Aceh Jaya $(n=44)$, dengan menggunakan uji Chi Square dari 44 responden yaitu $100.0 \%$ diperoleh bahwa dari 26 orang ibu memiliki pengetahuan yang baik, terdapat 20 orang ibu dengan Pemberian MP-ASI baik, dan 6 orang ibu dengan Pemberian MP-ASI kurang baik. dan dari 18 orang ibu yang pengetahuan nya kurang baik, terdapat 7 orang ibu dengan Pemberian MP-ASI baik, dan 13 orang ibu dengan Pemberian MP-ASI Kurang baik.

Setelah dilakukan uji statistik (uji Chi-Square), diperoleh nilai P-Value=0,007 (P-Value $<0,05)$ bahwa ada hubungan pengetahuan ibu dengan pemberian makanan pendamping ASI di Gampong Atoeng Kecamatan Jaya, Kabupaten Aceh Jaya, $(n=44)$.

Hal ini didukung dengan teori yang dikemukakan oleh (Kodrat, 2010), Makanan pendamping ASI merupakan makanan atau minuman yang mengandung gizi diberikan kepada bayi berusia 6 bulan untuk memenuhi kebutuhan gizinya. Sebelum bayi berusia 24 bulan, sebaiknya ASI tetap diberikan dengan memberikan ASI terlebih dahulu baru kemudian memberikan MP-ASI Peranan MP-ASI sama sekali bukan untuk menggantikan ASI melainkan hanya untuk melengkapi ASI. MP-ASI merupakan makanan peralihan dari ASI ke makanan keluarga. Pengenalan dan pemberian makanan pendamping ASI harus dilakukan secara bertahap baik jenis, porsi, frekuensi, bentuk maupun jumlahnya, sesuai dengan usia dan kemampuan pencernaan bayi/anak. Makanan pendamping ASI dapat berupa bubur, tim, sari buah, biskuit. Pemberian makanan pendamping ASI yang cukup kualitas dan kuantitasnya penting untuk pertumbuhan fisik danperkembangan kecerdasan anak yang sangat pesat pada periode ini.

Menurut pendapat peneliti bahwa ada hubungan pengetahuan ibu dengan pemberian makanan pendamping ASI di Gampong Lambaroh, Kecamatan Jaya, Kabupaten Aceh Jaya, dikarenakan indikasi para ibu dengan umur yang produktif yaitu Masa Dewasa Awal 26-35 tahun, usia 26-35 tahun merupakan masa dewasa muda. Pada usia ini berfokus pada diri sendiri dan keluarga, perubahan kognitif dan psikologis yang terjadi cukup besar sehubungan dengan pendidikan dan pekerjaan. Selain itu Tingkat pendidikan sangat berpengaruh terhadap tingkat 
Journal of Healthcare Technology and Medicine Vol. 6 No. 2 Oktober 2020

Universitas Ubudiyah Indonesia

e-ISSN : 2615-109X

pengetahuan. Pendidikan mempunyai peranan penting dalam pembentukan kecerdasan manusia maupun perubahan tingkah lakunya.

Tidak dapat dipungkiri bahwa semakin tinggi pendidikan seseorang maka semakin mudah pula mereka menerima informasi. Pada akhirnya banyak pula pengetahuan yang dimilikinya, sebaliknya jika seseorang memiliki tingkat pendidikan yang rendah maka akan menghambat perkembangan sikap seseorang terhadap penerimaan informasi.

\section{Hubungan Sikap Ibu Dengan Pemberian Makanan Pendamping ASI}

Setelah dilakukan uji statistik (uji Chi-Square), diperoleh nilai P-Value $=0,005$ (P-Value $<0,05)$ bahwa ada hubungan sikap ibu dengan pemberian makanan pendamping ASI di Gampong Lambaroh, Kecamatan Jaya, Kabupaten Aceh Jaya.

Hal ini didukung dengan teori yang dikemukakan oleh (Yenrina, 2008), sikap seseorang berarti perasaan mendukung atau memihak (favorable) maupun perasaan tidak mendukung atau tidak memihak (unfavorable) pada objek tertentu, dan sikap merupakan kecenderungan potensial untuk bereaksi dengan cara tertentu apabila individu diharapkan pada stimulus yang menghendaki adanya respon. Pengertian sikap dalam penelitian ini adalah sikap responden terhadap pemberian MP-ASI yang tepat pada bayi. Menurut (Krisnatuti, 2002,) bahwa sikap terdiri atas tiga komponen yang saling menunjang yaitu: 1) komponen kognitif, yang berisi kepercayaan seseorang mengenai apa yang berlaku atau yang benar bagi obyek. Sikap kepercayaan datang dari apa yang telah dilihat atau apa yang telah diketahui. Misalnya seorang ibu yang mempunyai bayi 6-12 bulan mempunyai kepercayaan bahwa memberikan MP-ASI pada bayi harus sesuai dengan usia bayi. 2) komponen afektif, yang menyangkut masalah emosional subyektif seseorang terhadap suatu obyek sikap.

Hasil penelitian ini sejalan dengan penelitian yang dilakukan oleh (Sari, 2005) hubungan antara karakteristik ibu dan perilaku ibu dengan riwayat pemberian makanan pendamping asi (mp-asi) dini di wilayah Puskesmas Cimahi selatan, hasil penelitian menunjukkan bahwa responden yang memiliki sikap negatif serta riwayat pemberian MP-ASI dini tidak baik merupakan persentase tertinggi yaitu sebanyak $81,0 \%$ jika dibandingkan dengan riwayat pemberian MP-ASI dini baik 
Journal of Healthcare Technology and Medicine Vol. 6 No. 2 Oktober 2020

Universitas Ubudiyah Indonesia

e-ISSN : 2615-109X

.Begitupun responden yang memiliki sikap positif serta riwayat pemberian MPASI. merupakan persentase tertinggi yaitu sebanyak 58,2\%., (Sari, 2005).

Menurut pendapat peneliti bahwa ada hubungan sikap ibu dengan pemberian makanan pendamping ASI di Gampong Lambaroh, Kecamatan Jaya, Kabupaten Aceh Jaya karena untuk meningkatkan keberhasilan menyusui, maka ibu harus mempunyai sikap yang baik atau positif terhadap pemberian MP-ASI yang tepat karena sikap sangat penting dalam terbentuknya tindakan seseorang, dikarenakan sikap merupakan reaksi atau respon seseorang yang masih tertutup terhadap suatu stimulus atau objek. Berdasarkan pernyataan tersebut, maka dapat disimpulkan bahwa sikap yang positif akan menimbulkan satu bentuk perilaku yang diharapkan Dengan sikap yang positif terhadap risiko dari pemberian MP-ASI terlalu dini pada bayi maka akan timbul suatu perilaku yang positif pula yaitu memberikan MPASI yang tepat pada bayi yaitu pada usia di atas 6 bulan.

\section{KESIMPULAN}

1. Ada hubungan pengetahuan ibu dengan pemberian makanan pendamping ASI di Gampong Lambaroh, Kecamatan Jaya, Kabupaten Aceh Jaya.

2. Ada ada hubungan sikap ibu dengan pemberian makanan pendamping ASI di Gampong Lambaroh, Kecamatan Jaya, Kabupaten Aceh Jaya.

\section{SARAN}

1. Bagi Ibu

Diharapkan kepada ibu yang memiliki bayi untuk lebih sering mengikuti kegiatan posyandu dan penyuluhan yang diadakan di Gampong tersebut, dalam rangka meningkatkan pengetahuan dan mencari informasi kesehatan terutama dengan keterkaitan ketepatan pemberian MP-ASI.

2. Bagi Puskesmas

Diharapkan kepada Puskesmas mengarahkan Bidan desa untuk lebih rutin memberikan informasi mengenai MP-ASI yang tepat kepada ibu-ibu, hasil penelitian ini juga diharapkan dapat memberikan masukan pada tenaga kesehatan khususnya bidan, perawat dan Kader kesehatan untuk dapat meningkatkan program puskesmas dalam memberikan penyuluhan tentang makanan pendamping ASI di masyarakat khususnya kepadaibu - ibu yang mempunyai anak balita 
Journal of Healthcare Technology and Medicine Vol. 6 No. 2 Oktober 2020

Universitas Ubudiyah Indonesia

e-ISSN : 2615-109X

3. Bagi petugas kesehatan

Diharapkan kepada pihak petugas kesehatan yang bekerja di Puskesmas yang berada di Gampong tersebut, lebih meningkatkan program komunikasi, informasi, dan edukasi (KIE) tentang MP-ASI pada ibu-ibu hamil dan ibu yang mempunyai bayi umur 6-24 bulan dalam bentuk melakukan penyuluhan tentang MP-ASI yang tepat kepada ibu-ibu secara personal.

\section{DAFTAR PUSTAKA}

1. Aik 2009, Mengenal Makanan-makanan Pendamping ASI. Diakses pada 24 April 2017 http://ilmu keperawatan.wordpress.com.

2. Arief Tq, Mochammat. 2008. Pengantar Metodologi Penelitian Untuk Ilmu Keehatan UNS Press, Surakarta.

3. Arikunto, S. 2006. Prosedur Penelitian Untuk Pendekatan Praktik, Rineka Cipta. Jakarta

4. Depkes RI, 2006. Pedoman Umum Pemberian Makanan Pendamping ASI (MPASI) Lokal. Jakarta.

5. Hartono. 2008. SPSS 16.0 Analisis Data Statistika dan Penelitian. Pustaka : Pustaka Pelajar, Yogyakarta.

6. Krisnatuti, D, 2000. Menyiapkam Makanan Pendamping ASI. Cet. ke-2. Puspa Swara, Jakarta

7. Kodrat, Lianda., 2010. Dahsyatnya ASI dan Laktasi, Media Baca. Mart, Yogyakarta.

8. Martini 2009, Hubungan Pengetahuan ibu dengan ketepatan waktu pemberian makanan pendamping ASI di wilayah kerja Puskesmas tawangmangu

9. Sari, Irvani., 2005. Hubungan Pengetahuan dan Sikap Ibu Terhadap Perilaku Pemberian MP-ASI Pada Bayi 6-12 Bulan di Puskesmas Cimahi Selatan Kota Cimahi. Skripsi. Depok: FKM UI

10. Setyaningsih, Atik., 2007. Hubungan Karakteristik Ibu dengan Pemberian MPASI Dini pada Bayi Usia 0-6 Bulan di Posyandu Warna Sari Desa Glonggong 
Journal of Healthcare Technology and Medicine Vol. 6 No. 2 Oktober 2020

Universitas Ubudiyah Indonesia

e-ISSN : 2615-109X

\section{Nogosari Boyolali, Skripsi.}

11. Yenrina. 2008. Menyiapkan Makanan Pendampin, Puspa Swara, Jakarta. 